\title{
Transient Bioheat Equation in Breast Tissue: Effect of Tumor Size and Location
}

\author{
Sharmila Shrestha*, Gokul KC, Dil Bahadur Gurung \\ Department of Mathematics, School of Science, Kathmandu University, Kavre, Nepal \\ Email: sharmila.shrestha@student.ku.edu.np
}

\begin{abstract}
Thermoregulation of human body maintains the body core temperature at $37^{\circ} \mathrm{C}$. Body temperature rises due to the illness such as fever or heat stroke. The abnormal temperature distribution in breast tissue is caused by breast diseases like cysts, tumor, cancer etc. Most of the breast tumor, normally, develops in lobules and milk ducts at glandular layer of breasts. Medically, infrared breast imaging (thermography and mammography) is used to diagnose breast cancer, in which temperature distribution analysis plays a vital role. In this study, finite element method is used to solve one dimensional unsteady state bio-heat equation to find temperature distribution in the layers of normal and tumorous breast tissue with different size and location of tumor from areola. The results show that temperature variation of breast layers depend on size and location of tumor from areola. The temperature distribution of layers of tumorous breast tissue is higher than normal breast tissue. From the simulation results, it is observed that temperature of tumorous breast tissue achieved steady state earlier than normal breast tissue.
\end{abstract}

Keywords: Breast tumor; temperature distribution; FEM; bioheat equation.

\section{Introduction}

Human body is made up of 100 trillion cells [16]. Different tissues have different cells. Tumor is a mass of abnormal and uncontrolled growth of tissue caused by damage of cells. Tumor needs more nutrition for growth. So, blood perfusion and metabolic rate are high in tumor. Most of the breast tumor, normally, develops in lobules and milk ducts at glandular layer of breast. Breast cancer is the malignant tumor. It is the major health problem of women in developed and developing countries. Nowadays, it is increasing day by day. Nearly 1.7 million new cases of breast cancer and about 521,900 deaths were diagnosed among women worldwide in 2012 [5]. According to American cancer society [1], in 2017, about 252,710 new cases of breast cancer were diagnosed in women in US and in 2018, it was about 266,120. The society also estimated about 268,600 new cases of invasive breast cancer will be diagnosed among women in US in 2019 [2]. World Health Organization (WHO) [8] estimated that 627,000 women died from breast cancer in 2018, which is approximately $15 \%$ of all cancer deaths among women. In context of Nepalese women, it is the second most common malignancy after Cervical cancer [14, 20]. About 1700 new cases of breast cancer were diagnosed in Nepal in 2012 [14]. According to WHO data published in 2017 [3], breast cancer deaths in Nepal reached 1054 or $0.65 \%$ of total death and the age adjusted death rate is 9.21 per 100,000 of population.

Thermoregulation plays vital role to maintain temperature in human body. Temperature is a good indicator of human health. High body temperature is often caused by illness, such as fever or heat stroke [17]. The abnormal surface temperature distribution of the breast can indicate breast diseases like cysts, tumor, cancer etc $[13,28]$. The existence or continue development of breast tumor causes abnormal infrared thermal imaging of the breast $[19,27]$. Thermography (thermal imaging) of the breast is the recording of temperature patterns of the breast tissue to form an image (thermogram) of the temperature distribution on the surface of the breast. Breast thermography can be used for women of all ages with any breast size and density. The principle of thermography is based on the fact that the metabolism and blood perfusion in both developing breast cancer and precancerous tissue are always higher than in normal breast tissue [12, 25]. Mammogram, breast cancer screening tool, is a low-energy x-ray of the breast to detect and evaluate breast changes. It is used for early diagnose of breast cancer. The anatomical changes in breast tissue are detected by mammography but thermography detect 
physiological changes in breast tissue [7]. The sensitivity of thermography is increased with tumor size and give falls positive results [29]. But the sensitivity of mammogram is higher for older women (60-69 years age group) at $85 \%$ than younger women (age less than 50 years) at $64 \%$ [6, 29]. Also, it is painful and its x-ray is harmful (equivalent to smoking three cigarettes) [23, 29]. The average size of tumors undetected by thermography is $1.28 \mathrm{~cm}$ while $1.66 \mathrm{~cm}$ by mammography [19].

The study of temperature distribution on breast tumor has clinical importance for medical doctors in diagnosis, treatment and cure of breast diseases like cancer. A mathematical model is better for understanding the temperature profile of the normal and tumorous breast.

Saxena and Arya [33], Gurung et al. [15] studied temperature distribution in skin and subcutaneous tissue (SST) region under normal environmental and various physiological conditions. Saxena and Pardasani [34], Pardasani and Adlakha [31] studied the problems involving tumor in SST regions of human body. Agrawal et al. [10] studied the thermal distribution in dermal regions of human limbs with tumor. Osman and Afify [30] first used a hemispherical breast model with different tissue layers of uniform thickness. They developed a mathematical model of three dimensional temperature distribution of the normal woman's breast using the finite element method. Lawson [21] used the thermographic detection of breast cancer and observed that the local temperature of the skin over a tumor were significantly higher than normal skin temperature. Lawson and Chughtai [22] have established the regional temperature difference of breast skin surface over an embedded tumor. This difference was due to convection effect associated with increased blood perfusion and increased metabolism in tumor. Sudharsan and Ng [36] developed a two-dimensional model of surface temperature distribution of female breast with and without tumor. Makrariya and Adlakha [24] discussed the two dimensional finite element method in dermal tissues of human breast under different stages of development. It is known from the literature survey that no attempts have been made so far to study the temperature distribution in breast tissue in unsteady state case. So, one dimensional finite element model of temperature distribution in layers of breast tissue involving tumor in transient case have been developed.

\section{Mathematical Model}

The human breast is assumed to be in hemispherical in shape. In the study, breast is assumed to be divided into seven layers: epidermis, dermis, subcutaneous tissue, glandular layer, tumor, muscle and thoracic wall, as shown in Figure 1. Breast tumor can occur any layers of breast tissue but most of the breast cancer normally develops in lobules and milk ducts. So, in the study, tumor is assumed to be in glandular layer. Osman et al. [30], Sudharsan et al. [36], Mital et al. [26] and Shrestha et al. [35] have used hemispherical breast with length $72 \mathrm{~mm}$ from areola to body core. The same domain of breast is used in our study, in which the length of epidermis, dermis, subcutaneous tissue, glandular layer and muscle with thoracic wall are taken $1.5 \mathrm{~mm}, 3.5 \mathrm{~mm}, 5 \mathrm{~mm}, 50 \mathrm{~mm}$ and $72 \mathrm{~mm}$ from areola, respectively. As sketched on Figure 1, the thickness of epidermis, dermis, subcutaneous, glandular without tumor (before tumor region), glandular with tumor, glandular without tumor (after tumor region) and muscle with thoracic wall have been considered as $l_{1}, l_{2}-l_{1}, l_{3}-l_{2}, l_{4}-l_{3}, l_{5}-l_{4}, l_{6}-l_{5}$ and $l_{7}$ - $l_{6}$, respectively. Similarly, $T_{0}, T_{1}, T_{2}, T_{3}, T_{4}, T_{5}, T_{6}, T_{7}=T_{b}$ (body core temperature) are the nodal temperatures at a distances $x=0, x=l_{1}, x=l_{2}, x=l_{3}, x=l_{4}, x=l_{5}, x=l_{6}, x=l_{7}$, respectively. $T^{(i)}$ are temperature functions of sub-domain $I^{(i)}, i=1,2,3,4,5,6,7$, respectively.

Bioheat equation is used in the study of one dimensional model. In 1948, Harry H. Pennes [32] developed an equation for effect of blood perfusion and metabolic heat transfer within a living tissue. After Pennes, other models were developed, but due to simplicity and applicability this model has been widely used by many researchers for analysis of bioheat transfer phenomena in living tissue. This equation is written in simplified form as

$$
\underbrace{\rho c \frac{\partial T}{\partial t}}_{\text {Heat storage }}=\underbrace{\operatorname{div}(K \operatorname{grad} T)}_{\text {Diffusion }}+\underbrace{\omega_{b} \rho_{b} c_{b}\left(T_{b}-T\right)}_{\text {Bood Perfusion }}+\underbrace{Q_{m}}_{\text {Metabolism }}
$$

where, $\rho$ is density of tissue $\left[\mathrm{kg} / \mathrm{m}^{3}\right], c$ is specific heat of tissue $\left[\mathrm{J} / \mathrm{kg}{ }^{\circ} \mathrm{C}\right], K$ is thermal conductivity of tissue $\left[\mathrm{W} / \mathrm{m}{ }^{\circ} \mathrm{C}\right], t$ is time $[\mathrm{s}], \omega_{b}$ is volumetric blood perfusion rate per unit volume $[1 / \mathrm{s}], \rho_{b}$ is density of the blood $\left[\mathrm{kg} / \mathrm{m}^{3}\right], c_{b}$ is specific heat of the blood $\left[\mathrm{J} / \mathrm{kg}{ }^{\circ} \mathrm{C}\right], T_{b}$ is arterial blood temperature $\left[{ }^{\circ} \mathrm{C}\right], T$ is local temperature of tissue $\left[{ }^{\circ} \mathrm{C}\right], Q_{m}$ is metabolic heat generation rate $\left[\mathrm{W} / \mathrm{m}^{3}\right]$. 


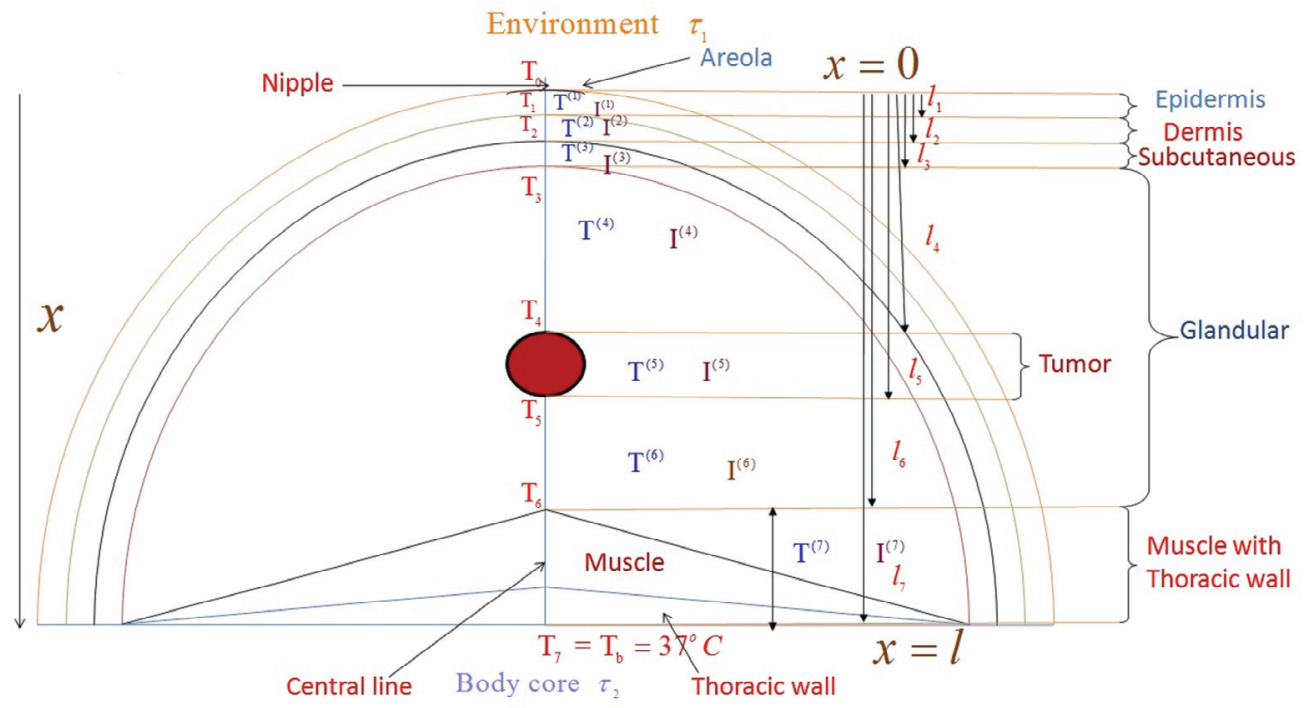

Figure 1. Schematic diagram of layers of breast tissue.

In the study, the length of the breast tissue measured from the areola to thoracic wall is assumed to be $l$ as shown in Figure 1 . Thus, $\Omega=[0, l]$ is domain of the study.

Skin, outer surface of the breast, is exposed to the environment from where heat loss takes place by convection, radiation and sweat evaporation. So the mixed boundary condition $[18,35]$ is

$$
\tau_{1}:\left.K \frac{\partial T}{\partial x}\right|_{x=0}=\underbrace{h_{\infty}\left(T-T_{\infty}\right)}_{\text {Convection term }}+\underbrace{\sigma \varepsilon\left(T^{4}-T_{\infty}^{4}\right)}_{\text {Radiation term }}+\underbrace{L E}_{\text {Sweat Evaporation }}
$$

where, $h_{\infty}$ is convection heat transfer coefficient between skin and subcutaneous tissue (SST) and ambient environment $\left[\mathrm{W} / \mathrm{m}^{2}{ }^{\circ} \mathrm{C}\right], T_{\infty}$ is Ambient room temperature $\left[{ }^{\circ} \mathrm{C}\right], \sigma$ is Stefan Boltzmann constant $\left(5.67 \times 10^{-8}\right)\left[\mathrm{W} / \mathrm{m}^{2}{ }^{\circ} \mathrm{C}^{4}\right], \varepsilon$ is emissivity of the $\mathrm{SST}\left[\mathrm{W} / \mathrm{m}^{2}\right], L$ is Latent heat of evaporation $[\mathrm{J} / \mathrm{kg}], E$ is sweat evaporation rate $\left[\mathrm{kg} / \mathrm{m}^{2} \mathrm{sec}\right]$.

Relation (2) can be written as

where, $h_{c r}=h_{\infty}+h_{\text {radiation }}$

$$
\begin{aligned}
\left.K \frac{\partial T}{\partial x}\right|_{x=0} & =h_{\infty}\left(T-T_{\infty}\right)+\sigma \varepsilon\left(T-T_{\infty}\right)\left(T+T_{\infty}\right)\left(T^{2}+T_{\infty}^{2}\right)+L E \\
& =\left[h_{\infty}+\sigma \varepsilon\left(T+T_{\infty}\right)\left(T^{2}+T_{\infty}^{2}\right)\right]\left(T-T_{\infty}\right)+L E \\
& =\left(h_{\infty}+h_{\text {radiation }}\right)\left(T-T_{\infty}\right)+L E \\
& =h_{c r}\left(T-T_{\infty}\right)+L E
\end{aligned}
$$

Thus,

$$
\tau_{1}:\left.K \frac{\partial T}{\partial x}\right|_{x=0}=h_{c r}\left(T-T_{\infty}\right)+L E
$$

The intersection between the breast base and breast is maintained at $37^{\circ} \mathrm{C}$. Thoracic wall is attached with body core. So the Dirichlet boundary condition in this part is

$$
\tau_{2}: T_{7}=T_{b}=37^{\circ} \mathrm{C}
$$

The variational form of the partial differential Equation (1) together with its boundary condition (3) is given by

$$
I\left[T(x, t)=\frac{1}{2} \int_{\Omega}\left[K\left(\frac{\partial T}{\partial x}\right)^{2}+\omega_{b} \rho_{b} c_{b}\left(T_{b}-T\right)^{2}-2 Q_{m} T+2 \rho c T \frac{\partial T}{\partial t}\right] d x+\frac{1}{2} h_{c r}\left(T-T_{\infty}\right)^{2}+L E T\right.
$$

Writing $I$ separately for each layer as: $I=\sum_{i=1}^{7} I_{i}$, where, 


$$
I_{i}=\frac{1}{2} \int_{l_{i-1}}^{l_{i}}\left[K^{(i)}\left(\frac{\partial T^{(i)}}{\partial x}\right)^{2}+\omega_{b} \rho_{b} c_{b}\left(T_{b}-T^{(i)}\right)^{2}-2 Q_{m}^{(i)} T^{(i)}+2 \rho c T^{(i)} \frac{\partial T^{(i)}}{\partial t}\right] d x+\frac{1}{2} h_{c r}\left(T_{0}-T_{\infty}\right)^{2}+L E T_{0}
$$

For minimization of $I$,

$$
\frac{d I}{d T_{i}}=0, \quad i=0,1,2,3,4,5,6
$$

Then system of equation (7) can be written in matrix form

$$
C \dot{T}+K T=R
$$

where, $\dot{T}=\left[\frac{\partial T_{1}}{\partial t}, \frac{\partial T_{2}}{\partial t}, \frac{\partial T_{3}}{\partial t}, \frac{\partial T_{4}}{\partial t}, \frac{\partial T_{5}}{\partial t}, \frac{\partial T_{6}}{\partial t}\right]^{\prime}, T=\left[T_{1}, T_{2}, T_{3}, T_{4}, T_{5}, T_{6}\right]^{\prime}$ and $C, K, \quad R$ are Capacitance, Conductance, Load vector matrices with dimension $7 \times 7,7 \times 7,7 \times 1$, respectively. Applying the Crank Nicolson method to solve the time derivative system (8) with respect to time and get the following relation

$$
\left(C+\frac{\Delta t}{2} K\right) T^{i+1}=\left(C-\frac{\Delta t}{2} K\right) T^{i}+\Delta t R
$$

where, $\Delta t$ is time interval.

The temperature increases from outer surface of breast towards thoracic wall when ambient temperature is less than $37^{\circ} \mathrm{C}$ and vice versa. Hence, we consider the temperature increases/decreases in linear order towards body core with regard to thickness. For initial nodal temperatures $T_{0}$ at time $t=0$, we assume the following initial condition

$$
T\left(x=l_{i}, t=0\right)=T(0,0)+\alpha l_{i}, \quad i=1,2,3,4,5,6,7 .
$$

where, $T(0,0)=22^{\circ} \mathrm{C}$ (It is because average normal skin surface temperature is assumed $22^{\circ} \mathrm{C}$ ) and $\alpha$ is constant to be determined. The relation (9) is repeatedly solved to get the required nodal temperatures.

\section{Numerical Results and Discussion}

Table 1. Parameter values used in model $[9,35,36]$

\begin{tabular}{lll}
\hline Parameter & Values & Units \\
\hline$K^{(1)}$ & 0.20934 & $\mathrm{~W} / \mathrm{m}^{\circ} \mathrm{C}$ \\
$K^{(2)}$ & 0.31401 & $\mathrm{~W} / \mathrm{m}^{\circ} \mathrm{C}$ \\
$K^{(3)}$ & 0.41868 & $\mathrm{~W} / \mathrm{m}^{\circ} \mathrm{C}$ \\
$K^{(i)}, i=4,5,6,7$ & 0.48 & $\mathrm{~W} / \mathrm{m}^{\circ} \mathrm{C}$ \\
$\omega_{b} \rho_{b} c_{b}$ & 2400 & $\mathrm{~W} / \mathrm{m}^{3 \circ} \mathrm{C}$ \\
$Q_{m}$ & 700 & $\mathrm{~W} / \mathrm{m}^{3}$ \\
$\rho$ & 1050 & $\mathrm{~kg} / \mathrm{m}^{3}$ \\
$C$ & 3475.044 & $\mathrm{~J} / \mathrm{kg}^{\circ} \mathrm{C}$ \\
$h_{c r}$ & 13.5 & $\mathrm{~W} / \mathrm{m}^{2 \circ} \mathrm{C}$ \\
$L$ & $2.4 \times 10^{6}$ & $\mathrm{~J} / \mathrm{kg}^{\circ}$ \\
$T_{b}$ & 37 & ${ }^{\circ} \mathrm{C}$ \\
$T_{\infty}$ & 21 & ${ }^{\circ} \mathrm{C}$ \\
$E$ & 0 & $\mathrm{~kg} / \mathrm{m}^{2} \mathrm{sec}$ \\
\hline
\end{tabular}

Sudharsan et al. [36], Mital et al. [26], and Shrestha et al. [35] considered the tumor as a highly perfused tissue like liver and thyroid gland. They have considered the value of perfusion and metabolism rates for tumor respectively as 20 and 2 times of muscle, skin respectively as $1 / 3$ and $4 / 7$ times of muscle, and glandular has the same value as muscle. The same values are considered in the study. In clinical environment, the thermographic measurement is set at the environmental temperature normally equal to $21^{\circ} \mathrm{C}[21,26,35,36]$. The same value for environment is used in this study. The other parameter values are taken as in Table 1. 


\subsection{Effect of Tumor Size in Temperature of Breast Tissue}

The Figure 2 presents the graphs of the temperature distribution on the layers of the breast tissue in case of normal and tumor with different tumor size having tumor center $18 \mathrm{~mm}$ from the areola. The result shows that temperature of each layers of tumorous breast is higher than normal and tissue temperature increases with the increase in tumor size. The graphs exhibit that the surface temperature of normal breast is $31.27^{\circ} \mathrm{C}$ and tumorous breast are $31.81^{\circ} \mathrm{C}, 32.04^{\circ} \mathrm{C}$ and $32.22^{\circ} \mathrm{C}$ of tumor size $7 \mathrm{~mm}$, $12 \mathrm{~mm}$ and $15 \mathrm{~mm}$, respectively. In breast tissue, the metabolic rate and blood perfusion rate decrease from thoracic wall to areola due to the concentration of vasculature decreases from the thoracic wall towards areola [4]. It then causes the temperature rise in the in-vivo breast tissue than breast skin surface. In our study, in-vivo breast tissue temperature is obtained higher than surface temperature of breast. Sudharsan et al. [36] observed in their study that the difference between normal and tumorous skin surface temperature of breast was $0.4^{\circ} \mathrm{C}, 0.7^{\circ} \mathrm{C}$ and $0.95^{\circ} \mathrm{C}$ in the tumor size $7 \mathrm{~mm}, 12 \mathrm{~mm}$ and 15 $\mathrm{mm}$, respectively. In our study, we have observed that the skin surface temperatures of tumorous breast rise by $0.54^{\circ} \mathrm{C}, 0.78^{\circ} \mathrm{C}$ and $0.96^{\circ} \mathrm{C}$ in the tumor size $7 \mathrm{~mm}, 12 \mathrm{~mm}$ and $15 \mathrm{~mm}$, respectively than normal. The slight variation in our results may be consideration of different layers in the skin of breast.

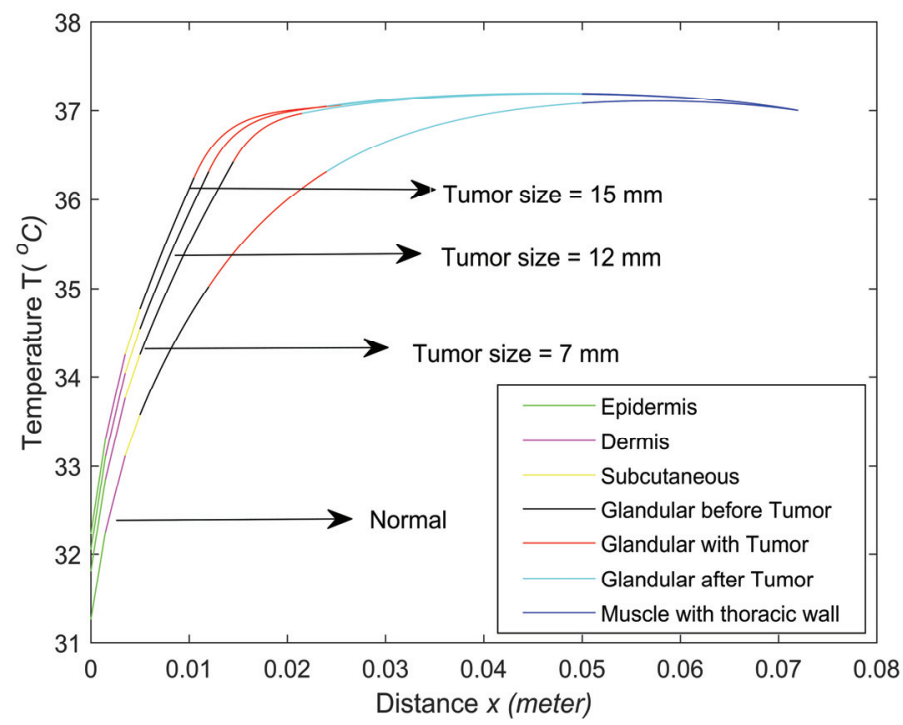

Figure 2. Temperature distribution profile on breast layers with and without tumor at different size: steady state case.

\subsection{Effect of Tumor Depth from Areola in Temperature of Breast Tissue}

In Figure 3, we have compared the temperature distribution profile of normal breast tissue with different location of tumor having tumor size $15 \mathrm{~mm}$. The graph shows that the surface temperature of normal breast is $31.27^{\circ} \mathrm{C}$ and tumorous breast are $32.69^{\circ} \mathrm{C}, 31.61^{\circ} \mathrm{C}$ and $31.42^{\circ} \mathrm{C}$ of tumor center $15 \mathrm{~mm}$, $25 \mathrm{~mm}$ and $30 \mathrm{~mm}$, respectively from the areola. Skin surface temperature is higher when tumor is closer to skin surface $[11,35]$. In our study, we observed the similar behavior of temperature rising in skin surface of breast. The result shows that the skin surface temperature is rising by $1.42^{\circ} \mathrm{C}, 0.35^{\circ} \mathrm{C}, 0.15^{\circ} \mathrm{C}$ than normal breast tissue with tumor center $15 \mathrm{~mm}, 25 \mathrm{~mm}$ and $30 \mathrm{~mm}$, respectively from areola. From the temperature profile, it is observed that the breast skin surface temperature is increased when tumor is nearest to skin surface and decreased when tumor is farthest away from skin surface. 


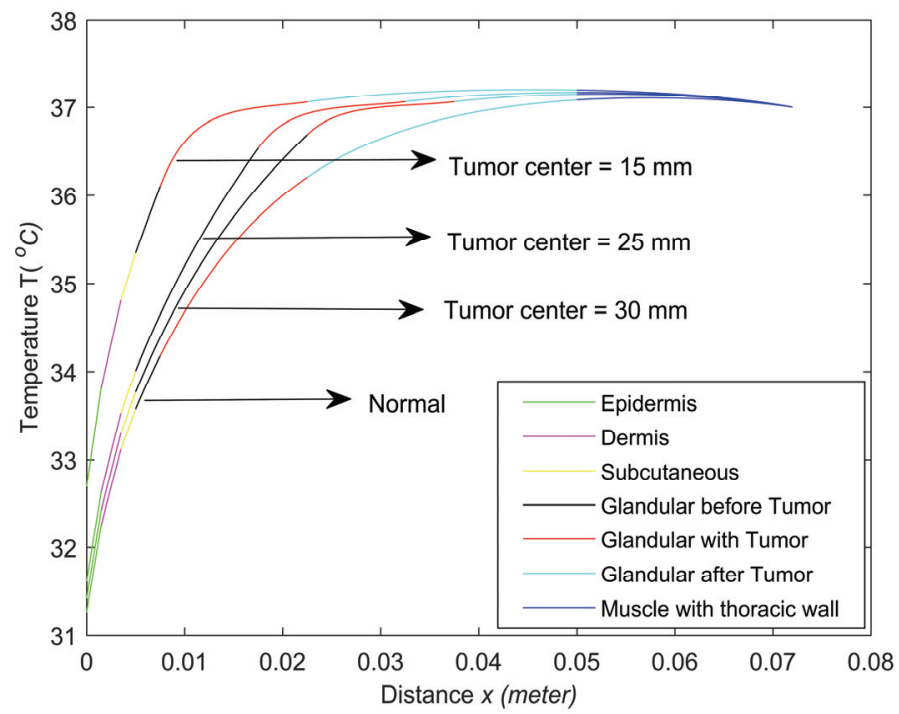

Figure 3. Temperature distribution profile on breast layers with and without tumor at different location: steady state case.

\subsection{Transient Result of Normal Breast Tissue}

Transient temperature distribution profile on normal breast tissue layers are shown in Figure 4. From the result, it is observed that the skin surface temperature reach steady state after 7000 seconds for the thickness $72 \mathrm{~mm}$ between areola and thoracic wall. Acharya et al. [9] observed in their study of human dermal part that the temperature of skin surface takes 15 seconds to reach steady state for $9 \mathrm{~mm}$ domain size. Similarly, KC et al. [18] observed that the surface temperature of human eye take 3600 seconds for $25 \mathrm{~mm}$ domain size to reach steady state. The result shows that tissue takes long time to achieved steady state temperature for larger domain size.

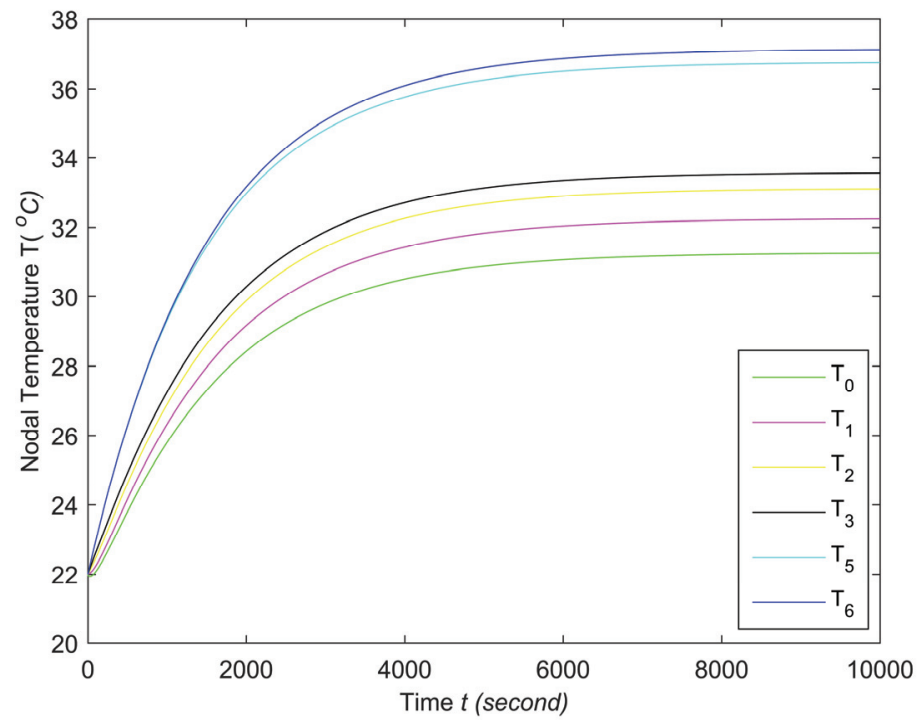

Figure 4. Temperature distribution profile on normal breast layers: transient case. 


\subsection{Transient Result of Tumorous Breast Tissue}

The transient temperature distribution profile on tumorous breast layers is shown in Figure 5 with tumor size $15 \mathrm{~mm}$ and tumor center $25 \mathrm{~mm}$ from areola. In presence of tumor, metabolic heat generation and blood perfusion rates are higher than healthy tissue [11, 26, 35, 36], which causes the higher temperature in tumor. The exhibit graph shows that the anterior temperature (T4) and posterior temperature (T5) of tumor region are achieved steady state earlier than other layers of breast tissue. From the simulation result, it shows that the anterior and posterior temperature of tumor region rises rapidly than other interface temperature of breast layers due to high impact of metabolic and blood perfusion in tumor. The anterior and posterior temperature of tumor region reach steady state at $36.53^{\circ} \mathrm{C}$ and $37.03^{\circ} \mathrm{C}$ after 2000 and 2500 seconds respectively. Similarly, the skin surface temperature $\left(T_{0}\right)$ reach steady state at $31.60^{\circ} \mathrm{C}$ after 3000 seconds. Muscle layer is close to body core and far from skin surface of breast tissue. Also, it is far from tumor when tumor is closer to skin surface. So, the interface temperature of glandular and muscle layer takes more time to achieve steady state than other layers of breast tissue. From Figures 4 and 5, it is observed that each layers of tumorous breast tissue are achieved steady state earlier than normal.

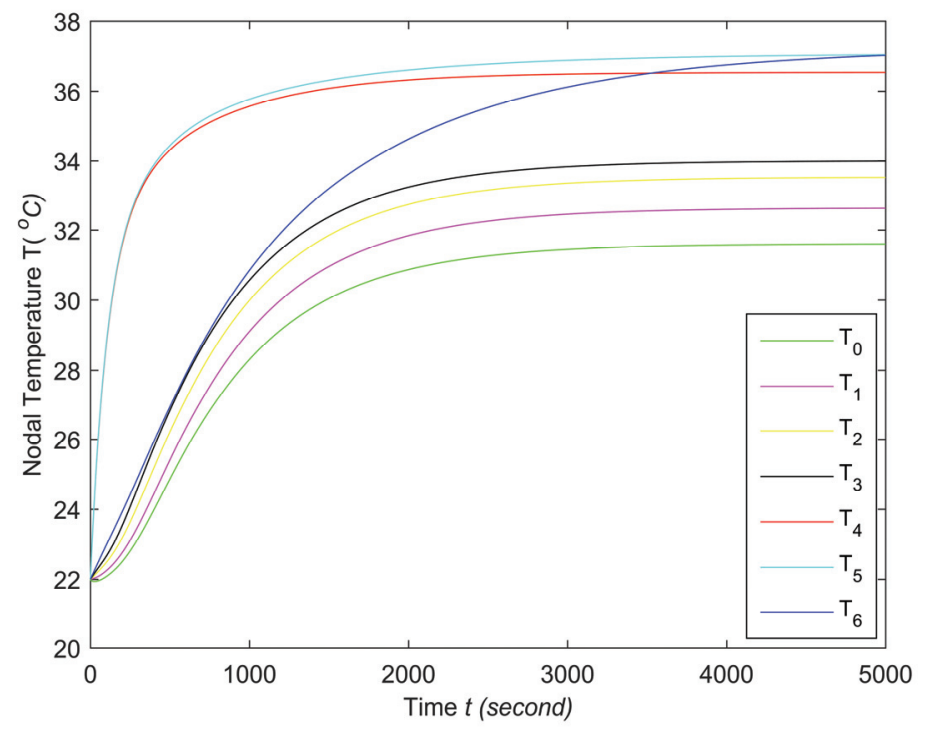

Figure 5. Temperature distribution profile on tumorous breast layers: transient case.

\subsection{Transient Skin Surface Temperature with Different Tumor Size and Location}

The surface temperature distribution profile on breast tissue with different tumor size and location are shown in Figure 6 and Figure 7, respectively. Temperature profile of tumorous breast is depended on size and location of tumor $[35,36]$. In Figure 6, skin surface temperature is compared with different tumor size $7 \mathrm{~mm}, 12 \mathrm{~mm}$ and $15 \mathrm{~mm}$ having tumor center $18 \mathrm{~mm}$ from areola. Increase in tumor size decreases the distance between areola and tumor. From the simulation result, it is observed that the skin surface temperature goes up rapidly with increase in tumor size and achieved study state earlier than smaller size of tumor. The steady state skin surface temperature of tumor size $15 \mathrm{~mm}$ is rising by $0.18^{\circ} \mathrm{C}$ and $0.45^{\circ} \mathrm{C}$ than $12 \mathrm{~mm}$ and $7 \mathrm{~mm}$ tumor size. In Figure 7 , skin surface temperature is compared with different tumor center $15 \mathrm{~mm}, 25 \mathrm{~mm}$ and $30 \mathrm{~mm}$ from areola at tumor size $15 \mathrm{~mm}$. Tumor is closer to skin surface when tumor center is nearest from areola. From the exhibit graph, the result shows that when tumor is closed to skin surface, the skin surface temperature rises rapidly and reach steady state earlier than other location of tumor. The result shows that the skin surface temperature of tumorous breast with different tumor size and location is achieved steady state earlier when tumor is closed to skin surface of breast. 


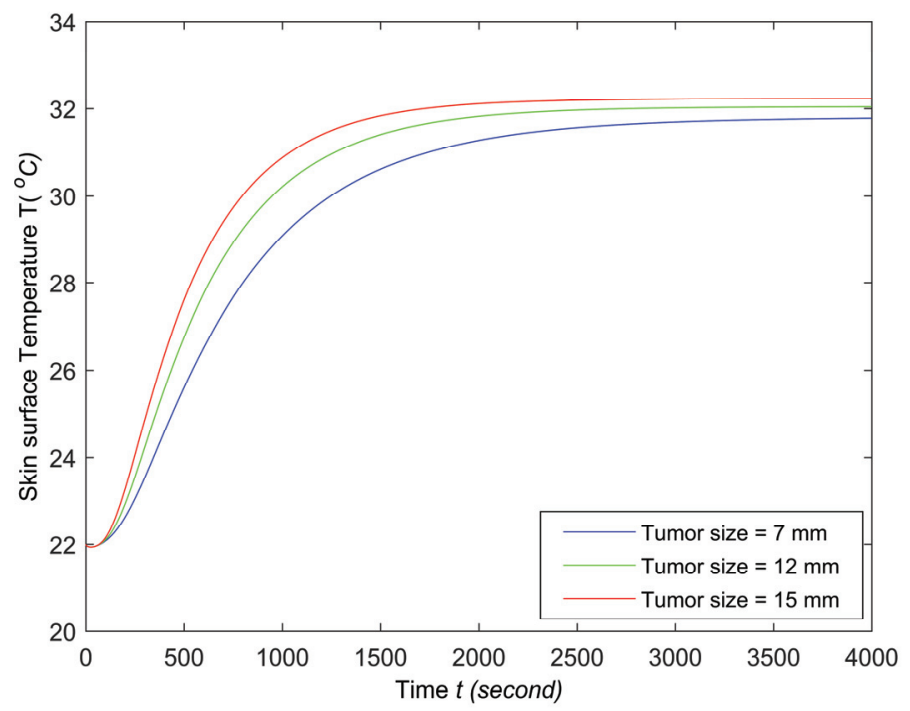

Figure 6. Skin surface temperature profile with different tumor size: transient case.

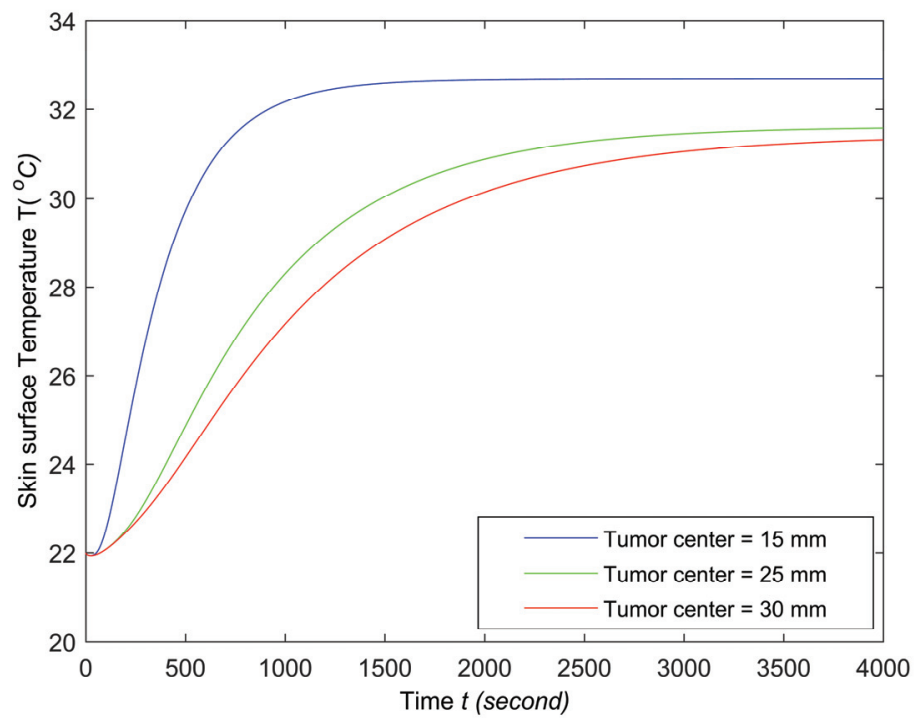

Figure 7. Skin surface temperature profile with different tumor location: transient case.

\subsection{Transient Result of Tumor Region with Different Size and Location of Tumor}

Figures 8 and 9 present the temperature profile of tumor region with different tumor size and location from areola. The solid curves represent the anterior temperature of tumor region and dotted curves represent the posterior temperature of tumor region. In Figure 8, anterior and posterior temperature of tumor region are compared with different tumor size $7 \mathrm{~mm}, 12 \mathrm{~mm}$ and $15 \mathrm{~mm}$ at tumor center $18 \mathrm{~mm}$ from areola. In Figure 9, anterior and posterior temperature of tumor region are compared with different tumor center $15 \mathrm{~mm}, 25 \mathrm{~mm}$ and $30 \mathrm{~mm}$ from areola at tumor size $15 \mathrm{~mm}$. In both cases, anterior part of the tumor regions are closed to skin surface which gives the result that anterior temperature of tumor region is achieved steady state earlier than posterior temperature of tumor region. 


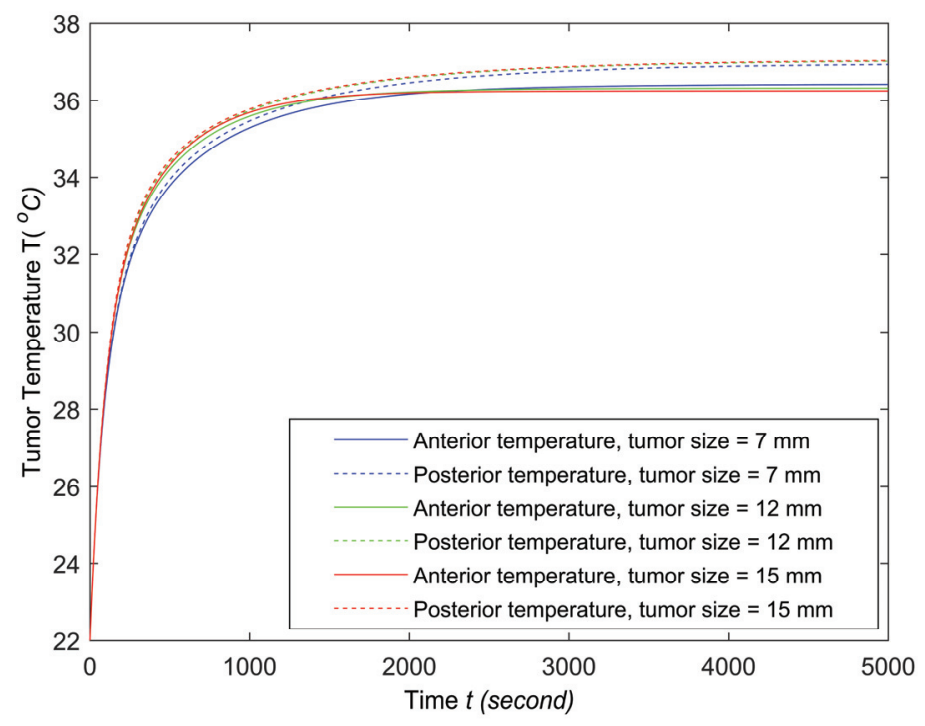

Figure 8. Temperature distribution profile of tumor on breast tissue with different tumor size.

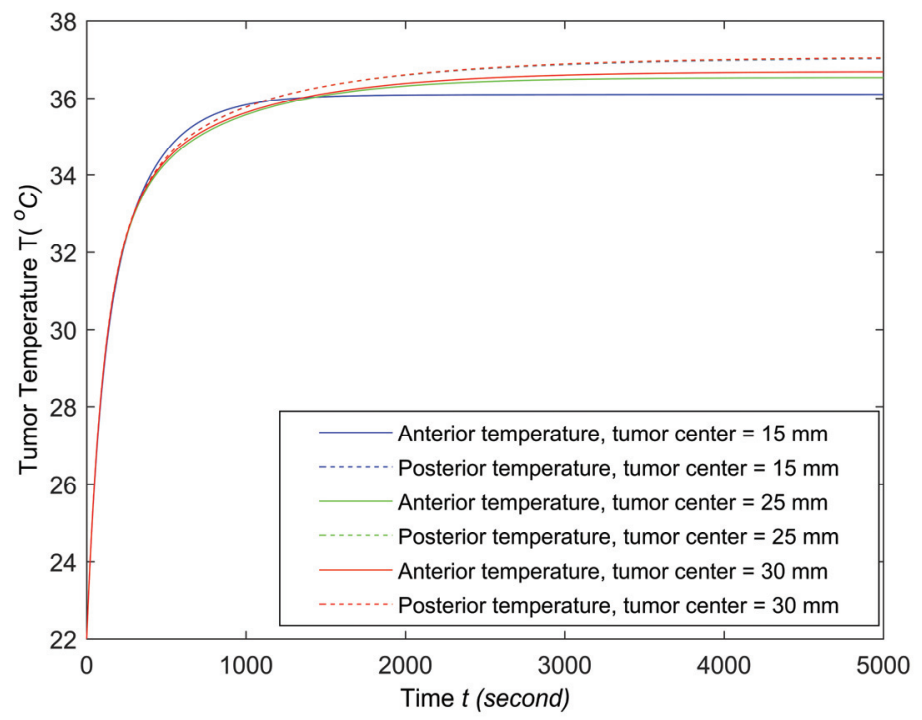

Figure 9. Temperature distribution profile of tumor on breast tissue with different tumor location.

\section{Conclusions}

In this study, steady and transient state temperature distribution of human female breast is computed using one dimensional finite element method with and without tumor. From the study, the following conclusions are made

I. Temperature distribution in each layer of tumorous breast tissue is higher than normal.

II. Increase in tumor size increases breast surface temperature.

III. Increase in tumor center from areola decreases breast surface temperature.

IV. The temperatures of tumorous breast tissue reach steady state earlier than normal breast tissue.

V. Temperature of muscle layer of tumorous breast tissue takes more time to reach steady state if tumor is far from it and vice-versa.

VI. The temperatures of tumor region reach steady state earlier than other layers of breast tissue.

VII. Skin surface temperature of normal breast reaches steady state after 7000 seconds whereas tumorous breast reach after 3000 seconds. It depends on size and location of tumor. 
VIII. The interface temperature of glandular and muscle layer takes more time to achieve steady state than other layers of breast tissue.

IX. The skin surface temperature of tumorous breast with different tumor size and location is achieved steady state earlier when tumor is closed to skin surface of breast.

$\mathrm{X}$. The anterior temperature of tumor region is achieved steady state earlier than posterior temperature of tumor region.

Acknowledgement. This study is funded to the first author by the University Grants Commission (UGC) Nepal, under the UGC PhD Fellowship (Award No: PhD /74 - 75/ S \& T - 11). We would like to acknowledge University Grants Commission, Nepal. We also like to acknowledge to the anonymous reviewers for their constructive comments and suggestions.

\section{References}

1. American Cancer Society, Available: http://www.cancer.org/Cancer facts and Figures 2017.

2. American Cancer Society, Available: http://www.cancer.org/Cancer facts and Figures 2019.

3. Breast Cancer in Nepal, Available: World Life Expectancy, https://www.worldlifeexpectancy.com/nepal-breastcancer.

4. Chapter 7: Vessels, lymphatic drainage and the breast, Available: https://.dartmouth.edu/ humananatomy /part_2/ chapter 7 .html.

5. Global cancer statistics, 2012, Available: https://onlinelibrary.wiley.com/doi/full/10.3322/caac.21262.

6. Singapore Cancer Registry, 1999, Ministry of Health, 3 Second Hospital Avenue, Singapore 168937, Available: http://www.gov.sg/moh/hfacts/hfacts.html.

7. South Avenue Women's Services, 2017, Available: https://www.southavewomensservices.com/whats-thedifference-between-mammography-and-thermography/.

8. World Health Organization, 2018, Available: http://www.who.int/cancer/prevention/diagnosis-screening/breastcancer/en/.

9. S. Acharya, D.B. Gurung and V. P. Saxena, "Effect of metabolic reaction on thermoregulation in human males and females body", Journal of applied mathematics, vol. 4, pp. 39-48, 2013.

10. M. Agrawal, N. Adlakha and K. Padarsani, "Thermal distribution in dermal regions of human limbs involving metastasis of tumors", International mathematical forum, vol. 5, no. 39, pp. 1903-1914, 2010.

11. K. Das and S. C. Mishra, "Estimation of tumor characteristics in a breast tissue with known skin surface temperature", Journal of thermal biology, vol. 38, pp. 311-317, 2013.

12. S. C. Fok, E. Y. K. Ng and K. Tai, "Early detection and visualization of breast tumor with thermogram and neural network", J Mech Med Biol, pp. 85-195, 2002.

13. M. Gautherie, "Temperature and blood flow patterns in breast cancer during natural evolution and following radiotherapy", Biomedical thermology, pp. 21-64, 1982.

14. M. Giri, R. J. Thapa, B. Upreti and B. Pariyar, "Breast cancer in Nepal: Current status and future directions", Biomedical reports, vol. 8, no. 4, 325-329, 2018. DOI: http://doi.org/10.3892/br.2018.1057.

15. D. B. Gurung, V. P. Saxena and P. R. Adhikary, "Fem approach to one dimensional unsteady state temperature distribution in the dermal parts with quadratic shape function", J.Appl. math and informatics, vol. 27, pp. 301- 313, 2009 .

16. C. Guyton and E. Hall, Text book of medical physiology. Elsevier, 2009.

17. S. Jha, P. K. Sharma and R. Malviya, "Hyperthermia: role and risk factor for cancer treatment", Achievements in the life sciences, vol. 10, pp. 161-167, 2016. DOI: http://doi.org/10.1016/j.als.2016.11.004.

18. Gokul KC, D. B. Gurung and P. R. Adhikary, "Fem approach for transient heat transfer in human eye", Applied mathematics, vol. 4, pp. 30-36, 2013.

19. J. R. Keyserlingk, P. D. Ahlgren, N. Belliveau and E. Yu, "Infrared imaging of breast: Initial reappraisal using high-resolution digital technology in 100 successive cases of stage I and II breast cancer", IEEE Transactions on Microwave Theory and Techniques, vol. 4, no. 4, pp. 241-251, 1998.

20. G. M. Khan, R. K. Thapa, D. S. Adhikari, M. Rajbhandari, P. Dwa, S. Shrestha and S. Oli, "Cancer prevalence trend in central region of Nepal", Journal of chitwan medical college, vol. 3, no. 3, pp. 22- 25, 2013.

21. R. N. Lawson, "Implications of surface temperatures in the diagnosis of breast cancer", Canadian medical association journal, vol. 75, pp. 309-310, 1956. 
22. R. N. Lawson and M. S. Chughtai, "Breast cancer and body temperatures", Canadian medical association journal, vol. 88, pp. 68-70, 1963.

23. H. A. Leong, "Breast cancer kills: does early detection make a differnence? Public symposium on cancer", Singapore Cancer Society, Singapore, 1998.

24. A. Makrariya and N. Adlakha, "Two dimensional finite element method of temperature distribution in dermal tissues of human breast under different stages of development", Available: http://www.researchgate.net/ publication/280623090, 2015.

25. M. Milosevic, D. Jankovic and A. Peulic, "Thermography based breast cancer detection using texture features and minimum variance quantization”, EXCLI Journal, vol. 13, pp. 1204-1215, ISSN 1611-2156, 2014.

26. M. Mital and R. M. Pidaparti, "Breast tumor simulation and parameters estimation using evolutionary algorithms", Hindawi Publishing Corporation modelling and simulation in engineering, 2008.

27. E. Y. K. Ng, "A review of thermography as promising non-invasive detection modality for breast tumor", International journal of thermal sciences, vol. 48, pp. 849-859, 2008.

28. E. Y. K. Ng, Y. Chen and L. N. Ung, "Computerized breast thermography: study of image segmentation and temperature cyclic variations", Journal of medical engineering and technology, vol. 25, no. 1, pp. 12-16, 2001.

29. E. Y. K. Ng and N. M. Sudarshan, "An improved three-dimensional direct numerical modeling and thermal analysis of a female breast with tumor", Proceedings of the Institution of Mechanical Engineers. Part H, journal of engineering in medicine, vol. 215, no. 1, pp. 25-37, 2001.

30. M. M. Osman and E. M. Afify, "Thermal modeling of the normal womans breast", Journal of biomechanical engineering, vol. 106, no. 2, pp. 123-130, 1984. [PubMed: 6738016].

31. K. R. Pardasani and N. Adlakha, "Exact solution to a heat flow problem in peripheral tissue layers with a solid tumor in the dermis", Ind. J. Pure. Appl. Math., vol. 22, no. 8, pp. 679-687, 1991.

32. H. H. Pennes, "Analysis of tissue and arterial blood temperature in resting forearm", Journal of applied physiology, vol. 1, pp. 93-122, 1948.

33. V. P. Saxena and D. Arya, "Steady state heat distribution in epidermis and subdermal tissue", J. Theor. Biolo, vol. 102, pp. 227-286, 1983.

34. V. P. Saxena and K. R. Pardasani, "Effect of dermal tumors on temperature distribution in skin with variable blood flow", Bulletin of mathematical biology, vol. 53, no. 4, pp. 525-536, 1991.

35. S. Shrestha and D. B. Gurung, "Finite element method approach for thermal analysis of female breast tissue tumor model. J Appl bioinforma Comput Biol, vol. 6, no. 3, 2017. DOI: http://doi.org/10.4172/23299533.1000141.

36. N. M. Sudarshan and E. Y. K. Ng, "Surface temperature distribution of a breast with and without tumour", Computer methods in biomechanics and biomedical engineering, vol. 2. No. 3, pp. 187-199, 1999 [PubMed: 11264827]. 